\title{
Assessment and prediction system of sustainable development
}

\author{
HAN Yixuan ${ }^{1, a}$ \\ ${ }^{1}$ Department of North China Electric Power University, Baoding, China \\ ${ }^{\mathrm{a}} 642096249$
}

Keywords: Coordination Coefficient; Entropy Method; demarcation point

\begin{abstract}
In this paper, an effective model is constructed to discuss the sustainability of a country. We define Coordination Coefficient (CC) to measure the sustainability of a country or a policy and use the value of CC to define how and when a country is sustainable or unsustainable. To consider all the possible parameters connected to the sustainability of a country, we divide them into four aspects: Society, Humanity, Resource and Economy. For each aspect, we use Entropy Method to determine the weight of its parameters. CC is defined by analyzing the mutual influence and restriction between aspects and parameters. The point when CC is zero can be roughly recognized as the demarcation point of sustainability and unsustainability. For more accuracy, cluster is used to determine the demarcation point. To prove the accuracy of the model, we select the countries which need the most support and intervention and introduce the concept "Ecological Footprint" to measure their sustainability and ecological demands. Then we use Time series prediction is used to predict the exact year when a country will be sustainable.
\end{abstract}

\section{Introduction}

Sustainable development has drawn everyone's attention for a long time. Due to the deterioration of the global environment, it satisfies our desire to protect the ecological system, and an increasing number of countries have realized it important to keep sustainable. The concept was defined by The United Nations World Commission on Environment and Development (WCED) in its 1987 report Our Common Future as "Development that meets the needs of the present without compromising the ability of future generations to meet their own needs." However, how to conduct quantitative analysis has been a controversial problem. Different nations have different standards for it, no unified measures have been taken.

\section{MODEL FOR THE SUSTAINABILITY}

Parameters and Aspects. To measure the sustainability of a country, we should consider all the possible influence factors. Too many parameters need to be considered to obtain sustainable development. We divide them into four aspects to simplify the problem: humanity, economic, society and resource. For each aspect, four representative parameters are chosen to describe it:

Humanity: 1.Rural population rate 2.Health expenditure per capita 3.Public health expenditure 4.International homicides

Economy: 1.GDP per capita 2.GDP 3.GDP growth 4.CPI(2014 100)

Society: 1.Death rate(per 1000) 2.Anime among women 3.Life expectancy 4.Population density

Resource: 1.Freshwater per capita 2.Marine protected areas 3.Forest area(\%) 4.Food production index

\section{Model to Measure the Sustainability of a Country or a Policy}

To measure the sustainability of a country, coordination coefficient is introduced by describing the relationship between and in different aspects. We regard every aspect as a sub system, each sub system has a goal value. For each sub system, the score decided by Entropy Method can be considered as the development index of the sub system. For different sub systems, we can study the influence of different parameters. After thoughtful derivation, the coordination 
coefficient can be calculated.

Coordination Coefficient of a Sub. SystemConsidering the mutual influence between sub systems, We define coordination coefficient of sub systems as follow :

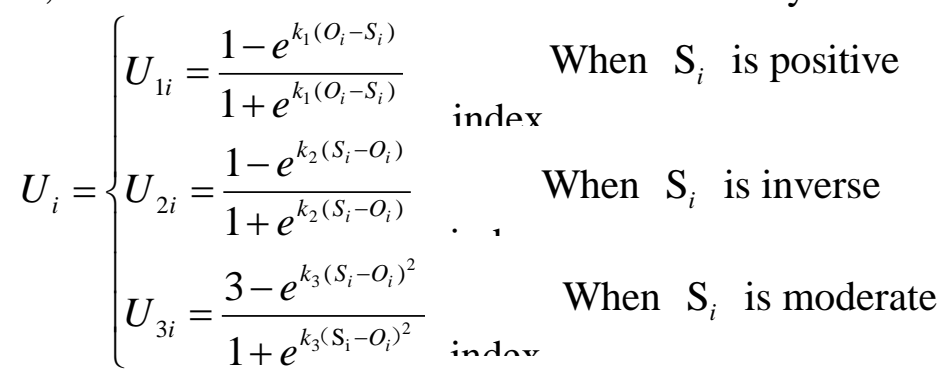

Where $O_{i}$ is the target goal of the $i_{\text {th }}$ aspect, $U_{i}$ is the coefficient of coordination of the $i_{\text {th }}$ sub system. $k_{1}, k_{2}$ and $k_{3}$ are coefficient, can be assigned as the constant greater than zero, the higher the value, the better the sensitivity.

Coordination Coefficient Between Sub Systems. For this part, we take the influence of parameters from different sub systems as consideration. The influence can be calculated as below:

$$
T_{i}^{p}=\sum_{q=1}^{n} T_{i}^{p q} S_{i}
$$

Where $T_{i}^{p}$ means the influence of the $p_{t h}$ parameter from the $i_{t h}$ sub system, $T_{i}^{p}$ means the influence between the $p_{\text {th }}$ parameter and $q_{t h}$ parameter.

$$
T_{i}=\sum_{p=1}^{n} \sum_{q=1}^{n} T_{i}^{p q} S_{i}
$$

Where $T_{i}$ means the influence that the $i_{\text {th }}$ sub system has.

$$
C_{i}=\frac{T_{i}}{\sum_{p=1}^{m} \sum_{q=1}^{n} T^{p q}} S_{i}
$$

Where $C_{i}$ means the coordination coefficient between sub systems.

The Total Coordination Coefficient. After working out the coordination coefficient in and between sub system, we can calculate the total coordination coefficient as below:

$$
C=\sum_{i=1}^{n} k_{i}\left(\alpha U_{i}+\beta C_{i}\right)
$$

Where $\sum_{i=1}^{n} k_{i}=1, \alpha+\beta=1$

Now the sustainability can be measured by coordination coefficient. We can all rank all the countries according to their coordination coefficient.

How to Judge a Country's Being Sustainable. The value of the coordination coefficient we define is between -1 and 1 . We can judge a country to be sustainable if its coordination coefficient is greater than zero, conversely, if a country's coordination coefficient is below zero, it should be regarded as unsustainable. To be more authentic, the model of cluster is built to distinguish sustainable countries from unsustainable countries. Below is the picture we obtain by using cluster. 


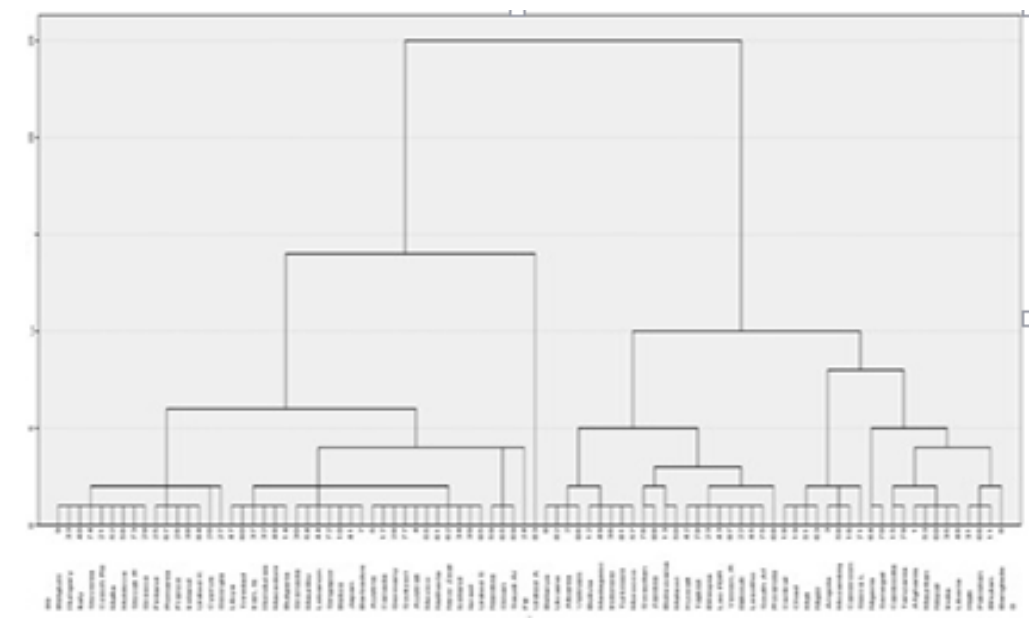

Fig 1: The cluster result

Measure the Sustainability of Countries

Entropy Method to Weigh Parameters.

Step1. Calculate the ratio of the country i with parameter $\mathrm{k}$.

$$
p_{i k}=\frac{x_{i}^{*}(k)}{\sum_{i=1}^{n} x_{i}^{*}(k)}
$$

Step2. Gain the entropy of parameter i.

$$
p_{i k}=-k \sum_{i=1}^{n} p_{i k} \ln p_{i k}
$$

Step3. Calculate the difference coefficient of parameter i. For parameter i, the bigger the difference of the data is, the greater the weight of the index is and the smaller the entropy. We define the difference coefficient as:

$$
\begin{gathered}
g_{k}=\frac{1-e_{k}}{m-E_{e}} \\
E_{e}=\sum_{k=1}^{m} e_{k}
\end{gathered}
$$

Where $\sum_{k=1}^{m} g_{k}=1$.

Step4. Calculate the weight.

$$
\omega_{k}=\frac{g_{k}}{\sum_{k=1}^{m} g_{k}}
$$

Since $\sum_{k=1}^{m} g_{k}=1$, the difference coefficient is equal to the weight.

Tab 1: Weight of parameters of different categories

\begin{tabular}{crrrr}
\hline Aspect & Parameter 1 & Parameter 2 & Parameter 3 & Parameter 4 \\
\hline E & 0.143081 & 0.603199 & 0.249236 & 0.004484 \\
S & 0.101596 & 0.503829 & 0.334127 & 0.060448 \\
R & 0.443172 & 0.096058 & 0.095138 & 0.365633 \\
H & 0.062178 & 0.351265 & 0.531745 & 0.054811
\end{tabular}

By using Entropy Method, we can get the weight of every parameter of each category,thus deciding the evaluation of a country in four aspects. The calculation can be done as below:

$$
S_{i}=\sum_{k=1}^{4} p_{k} \omega_{k}
$$


Where $S_{i}$ is the score of the $i_{t h}$ aspect, $p_{k}$ is the value of the $i_{t h}$ parameter.

Calculate the Total Coordination Coefficient. Based on the model we have built above, we calculate the coordination coefficient between system and the coordination coefficient of a system. The result as follow:

Tab 2: Top 8 sustainable countries

\begin{tabular}{cccccc}
\hline Country & $\mathrm{E}$ & $\mathrm{S}$ & $\mathrm{R}$ & $\mathrm{H}$ & $\mathrm{C}$ \\
\hline Norway & 0.160945 & 0.364999 & 0.119265 & 0.413015 & 0.858224 \\
Iceland & 0.082751 & 0.307107 & 0.466751 & 0.192405 & 0.849013 \\
Switzerland & 0.141962 & 0.403166 & 0.09124 & 0.401085 & 0.837453 \\
Japan & 0.205054 & 0.470295 & 0.10817 & 0.229964 & 0.813483 \\
Vietnam & 0.580517 & 0.300319 & 0.070704 & 0.060354 & 0.811893 \\
Sierra Leone & 0.026805 & 0.798543 & 0.082245 & 0.072052 & 0.779645 \\
Guinea & 0.049324 & 0.701909 & 0.114959 & 0.093776 & 0.759968 \\
Luxembourg & 0.172168 & 0.330111 & 0.114509 & 0.326453 & 0.743241 \\
\hline
\end{tabular}

Countries in need of Support and Intervention. We can tell the 10 least sustainable based on their total coordination coefficient. However, not all unsustainable countries need support. For some countries such as Japan, they may not have abundant natural resources, they can import resources from abroad to meet their demands. So we introduce the concept ecological footprint to select the countries which are in need of support indeed. Ecological footprint is a measurement of anthropogenic impact on earth. If a country does not have enough ecological resources within its own territory, then there is a local ecological deficit and it is called an ecological debtor country. Otherwise, it has an ecological remainder and it is called an ecological creditor country.

Tab 3: Top 10 Countries in need of support and intervention most

\begin{tabular}{ccccccc}
\hline Country Name & $\mathrm{E}$ & $\mathrm{S}$ & $\mathrm{R}$ & $\mathrm{H}$ & $\mathrm{C}$ & $\mathrm{EP}$ \\
\hline United Arab & 0.07306 & 0.11972 & 0.03607 & 0.06762 & -0.7035 & -9.83 \\
Jordan & 0.02385 & 0.25695 & 0.00456 & 0.06531 & -0.6493 & -1.81 \\
Oman & 0.03942 & 0.26875 & 0.01703 & 0.05553 & -0.6193 & -2.85 \\
Iraq & 0.04144 & 0.31314 & 0.00691 & 0.03468 & -0.6038 & -1.05 \\
Tunisia & 0.03016 & 0.33424 & 0.01862 & 0.05095 & -0.566 & -0.92 \\
Qatar & 0.13285 & 0.20666 & 0.01227 & 0.08384 & -0.5644 & -8 \\
Kuwait & 0.09186 & 0.25471 & 0.0315 & 0.06231 & -0.5596 & -5.92 \\
Timor-Leste & 0.02882 & 0.28944 & 0.06993 & 0.06079 & -0.551 & 0.77 \\
Algeria & 0.02718 & 0.36457 & 0.01446 & 0.05422 & -0.5396 & -1 \\
Albania & 0.02925 & 0.32783 & 0.05777 & 0.07643 & -0.5087 & -1.04 \\
\hline
\end{tabular}

\section{When Countries Become Sustainable}

We utilize the coordination coefficient defined above to judge a country's sustainability. As for when it becomes sustainable,

we divide the situations into two kinds. In one case, if a country becomes sustainable or unsustainable before, we can pick the year out according to the data we gather. In another, if a country will be sustainable or unsustainable in the future, to get the exact year, we build a time series prediction model to predict how the country develops.

The Time Series Prediction Model. Time series is time varying and related data series in chronological order. We use the tendency of moving average method to build it as below.

Suppose $y_{1}, \cdots, y_{t}$ is observation sequence, and $\mathrm{N}<\mathrm{t}$.

First moving average number:

$$
M_{t}^{(1)}=\frac{1}{N}\left(y_{t}+y_{t-1}+\cdots+y_{t-N+1}\right)
$$

Then move average number: 


$$
M_{t}^{(2)}=\frac{1}{N}\left(M_{t}^{(1)}+\cdots+M_{t-N+1}^{(1)}\right)=M_{t-1}^{(2)}+\frac{1}{N}\left(M_{t}^{(1)}-M_{t-N}^{(1)}\right)
$$

Suppose the time series $\left\{y_{t}\right\}$ have linear trend at a moment, and the trend will continue. Then, we can suppose the linear trend prediction model as below:

$$
\hat{y}_{t+m}=a_{t}+b_{t} m, m=1,2 \ldots
$$

Where $\mathrm{t}$ is the present moment, $\mathrm{m}$ is the period number to predict, $a_{t}$ is the intercept, $b_{t}$ is the slope.

According to it, get

$$
\begin{gathered}
a_{t}=y_{t} \\
M_{t}^{(1)}-M_{t}^{(2)}=\frac{N-1}{2} b_{t}
\end{gathered}
$$

Then we determine $a_{t}, b_{t}$ as below:

$$
\left\{\begin{array}{l}
a_{t}=2 M_{t}^{(1)}-M_{t}^{(2)} \\
b_{t}=\frac{2}{N-1}\left(M_{t}^{(1)}-M_{t}^{(2)}\right)
\end{array} .\right.
$$

With the calculation, we can predict the value of coordination coefficient of the future.

Predict the Tendency of Coordination Coefficient. First, we can calculate the coordination coefficient (CC) of a country in the past years with the data. Then, based on the previous data, we utilize the time series prediction model to predict the tendency, thus obtaining the coordination coefficient of the future, so we can judge when one country is sustainable.

For example, we collect the data of Croatia、India、Brazil dating from 1994 to 2012.By calculating coordination coefficient, we obtain the value by year. Picture is shown as below:

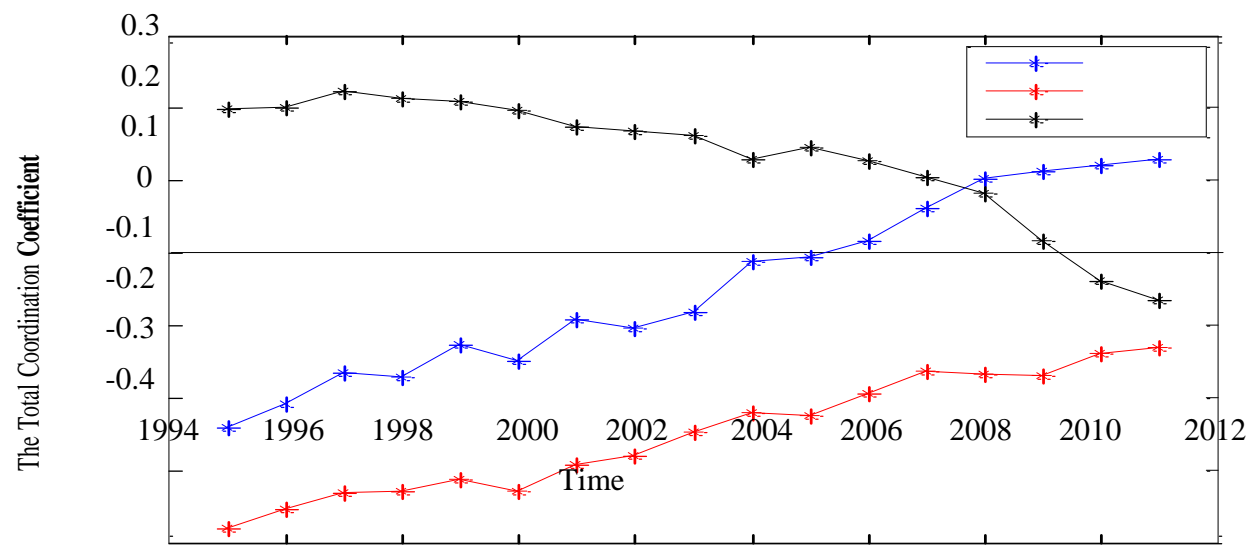

Fig 2: The value of CC of three countries by year

From this figure above, we can observe that Croatia adjusted from unsustainable development to sustainable development in the year 2004 approximately, While Brazil changed from sustainable development to unsustainable development in the year 2009 approximately. Since India has a tendency to turn to sustainable, so we can use the time series prediction model to predict the development of it, as can be seen from the picture below: 


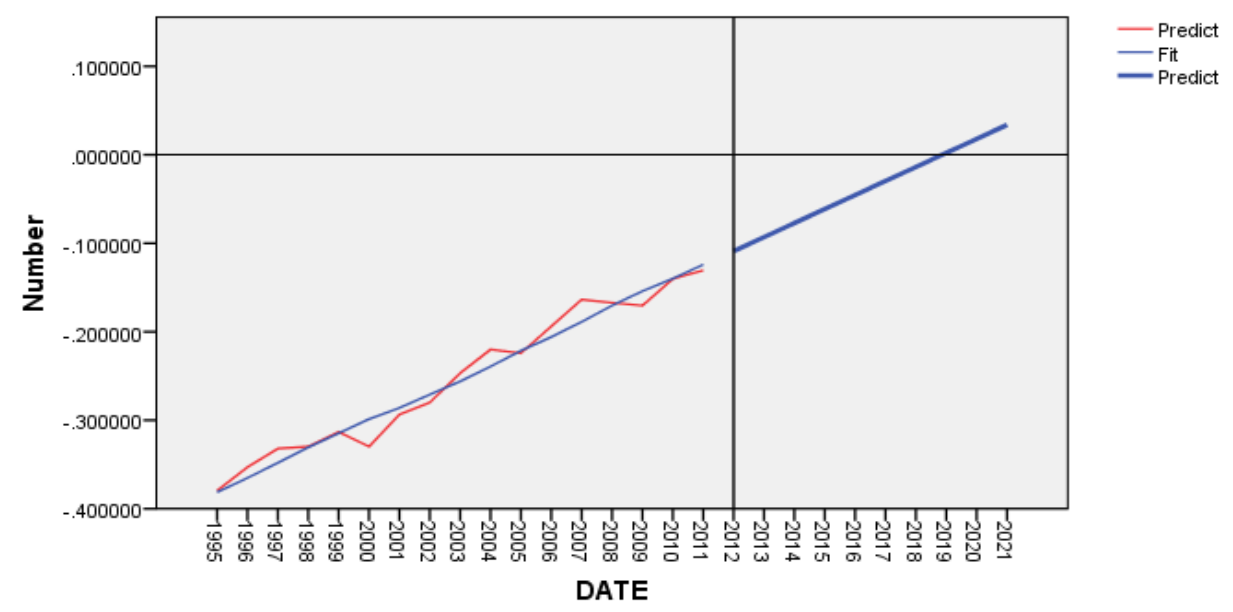

Fig 3: The value of CC of India by year

\section{Summary}

The main conclusions are summaried as follows:

(1)Since we process all data with objective methods, our results should be authentic and reasonable.

(2)The defined concept coordination coefficient considers the mutual interdependence, constraints and promotion of all the aspects of a country, can measure the sustainability in a more accurate way.

(3)Due to the lack of some special data, we have to do some proper assumptions while establishing models. A more abundant data resource can guarantee a better result in our models.

\section{References}

[1]http://unstats.un.org/unsd/demographic/products/socind/

[2]Brundtland G H. World Commission on environment and development .Environmental policy and law, 1985, 14(1): 26-30.

[3]http://en.wikipedia.org/wiki/Angola

[4] United Nations. The future we want. Resolution adopted by the General Assembly.66th Session of the General Assembly, 123rd plenary meeting; 2012 July 27. New York: UN; 2012 Sep 11 (Resolution A/RES/66/288) [cited 2013 July 23].

[5]Bell, Simon and Stephen Morse. 2008. Sustainability Indicators: measuring the immeasurable. Earthscan, London.

[6]Daly, Herman. 1990. Towards some operational principles of sustainable development. Ecological Economics, 2(1990) 1-6.

[7]Bell S, Morse S. Measuring the immeasurable. The Theory and Use of Sustainability Indicators in Development, Earthscan, London,1999.

[8]Dittmar M. Development Towards Sustainability: How to judge past and proposed policies. Science of The Total Environment, 2014, 472: 282-288.

[9]Zeng Z. The analysis of coordination and sustainable development. Syst. Eng.Theory Pract, 2001, 3: 18-21. 